\title{
The role of nutrition, intimate partner violence and social support in prenatal depressive symptoms in rural Ethiopia: community based birth cohort study
}

Yitbarek Kidane Woldetensay ${ }^{1,2,3^{*}}$ (D), Tefera Belachew ${ }^{3}$, Hans Konrad Biesalski ${ }^{1,2}$, Shibani Ghosh ${ }^{4}$, Maria Elena Lacruz ${ }^{6}$, Veronika Scherbaum ${ }^{1,2}$ and Eva Johanna Kantelhardt5,6

\begin{abstract}
Background: Depression during pregnancy has far-reaching adverse consequences on mothers, children and the whole family. The magnitude and determinants of prenatal depressive symptoms in low-resource countries are not well established. This study aims to describe the prevalence of prenatal depressive symptoms and whether it is associated with maternal nutrition, intimate partner violence and social support among pregnant women in rural Ethiopia.

Methods: This study is based on the baseline data from a large prospective, community-based, birth cohort study conducted in the South Western part of Ethiopia from March 2014 to March 2016. A total of 4680 pregnant women were recruited between 12 and 32 weeks of gestation. Depressed mood was assessed using the Patient Health Questionnaire (PHQ-9) scale and a cut off of $\geq 8$ was taken to define prenatal depressive symptoms. Data collection was conducted electronically on handheld tablets and submitted to a secured server via an internet connection. Bivariate and multivariate logistic regression analyses were computed using IBM SPSS version 20 software.

Result: The community based prevalence of depressive symptoms during pregnancy was $10.8 \%$ (95\%Confidence Interval (CI): 9.92-11.70). Adjusting for confounding variables, moderate household food insecurity (OR 1.74; 95\% Cl: 1.31-2.32), severe household food insecurity (OR 7.90; 95\% Cl: 5.87-10.62), anaemia (OR=1.30; 95\% Cl: 1.04-1.61) and intimate partner violence (OR 3.08; 95\% Cl: 2.23-4.25) were significantly associated with prenatal depressive symptoms. On the other hand, good social support from friends, families and husband reduced the risk of prenatal depressive symptoms by $39 \%$ (OR 0.61; 95\% Cl: 0.50-0.76).

Conclusion: Prenatal depressive symptomatology is rather common during pregnancy in rural Ethiopia. In this community based study, household food insecurity, anaemia and intimate partner violence were significantly associated with prenatal depressive symptoms. Good maternal social support from friends, families and spouse was rather protective. The study highlights the need for targeted screening for depression and intimate partner violence during pregnancy. Policies aimed at reducing household food insecurity, maternal anaemia and intimate partner violence during pregnancy may possibly reduce depression.
\end{abstract}

Keywords: Prenatal depression, Household food insecurity, Anaemia, Intimate partner violence, Social support, PHQ-9, Ethiopia

\footnotetext{
* Correspondence: yitbarek.woldetensay@gmail.com

${ }^{1}$ Institute of Biological Chemistry and Nutrition (140a), University of Hohenheim, Stuttgart, Germany

${ }^{2}$ Food Security Center, University of Hohenheim, Stuttgart, Germany

Full list of author information is available at the end of the article
}

(c) The Author(s). 2018 Open Access This article is distributed under the terms of the Creative Commons Attribution 4.0 International License (http://creativecommons.org/licenses/by/4.0/), which permits unrestricted use, distribution, and

reproduction in any medium, provided you give appropriate credit to the original author(s) and the source, provide a link to the Creative Commons license, and indicate if changes were made. The Creative Commons Public Domain Dedication waiver (http://creativecommons.org/publicdomain/zero/1.0/) applies to the data made available in this article, unless otherwise stated. 


\section{Background}

Major depression is the leading cause of the global burden of disease today [1]. It is also the most prevalent psychiatric disorder during pregnancy [2]. Prenatal depression can lead to serious health risks for both the mother and infant $[3,4]$. A recent systematic review revealed that in low- and lower-middle-income countries (LMICs) average prevalence of perinatal mental disorder (25.3\%: 95\% CI: $21.4-29.6 \%)$ was considerably higher than the 7-15\% prevalence in high-income countries [2]. Nonetheless, low-income countries assign about $0.5 \%$ of their health budget to mental health while high-income countries devote $5.1 \%$, an amount, still disproportionately small (given the prevalence and impact of mental disorders), to implement a series of highly cost-effective interventions [1].

In Ethiopia the prevalence of prenatal depression varies widely based on the instruments used and study settings. A $12 \%$ prevalence of prenatal depression was reported using PHQ-9 scale [4], 23\% using Beck Depression Inventory (BDI) scale [5], 25\% using Edinburgh Postnatal Depression Scale [6] and 31.5\% using WHO Self-Reported Questionnaire with 20 items (SRQ-20) [7]. A community based study showed a $12 \%$ prevalence of common mental disorder during pregnancy [4]. Whereas, health facility based studies revealed 23-31.5\% prevalence [5-7].

Based on previous research findings in low, middle and high income countries, socio-demographic factors such as age [5, 8], income [9] and educational attainment [7] were identified as factors affecting prenatal depressive symptoms. Clinical factors includes previous depression [8], concomitant high anxiety in pregnancy (Strewart et al., 2003) and a history of miscarriage and induced abortion $[10,11]$. Studies also showed that household food insecurity [12] and anaemia [13] are identified as nutrition related factors for prenatal depression. A number of studies also indicated that intimate partner violence is another factor associated with depression during pregnancy $[14,15]$.

Several studies have shown a role of nutrition in mental distress, and they mostly documented the psychological effects of nutrient deficiencies. These studies indicated that deficiencies in folate, vitamin B12, calcium, iron, selenium, zinc, and polyunsaturated fatty acids (PUFAs) are associated with depression. Particularly, omega-3 fatty acids are getting special attention regarding their efficacy in depression treatment [16]. Nutrition is a modifiable risk factor, and therefore is possible to be improved with targeted programs in addition to support programs to reduce maternal distress [17].

Studies exploring the association between maternal nutrition and prenatal depression are still inconclusive and the limited studies available did not control for important variables such as intimate partner violence and social support [18]. In Ethiopia, though the prevalence and determinants of intimate partner violence is well studied in the general population, there are limited data describing its association with prenatal depression [19]. This study aims to describe the prevalence of prenatal depression and whether it is associated with maternal nutrition, intimate partner violence and social support among pregnant women in rural Ethiopia.

\section{Methods}

This study utilizes baseline data from a prospective, community-based, quasi-experimental birth cohort study within Empowering New Generations to Improve Nutrition and Economic opportunities (ENGINE) program. ENGINE is a USAID funded program, which aims to improve nutritional status of mothers' and young children in Ethiopia through a multi-sectoral approach targeting health, nutrition and agriculture. The ENGINE birth cohort study was led by Tufts University and aimed to investigate the benefits of an integrated nutrition program and its co-location with agricultural growth program on household agricultural production and productivity, food security, diet diversity, socio-economic status and livelihoods, as well as health status, anthropometry and hemoglobin for mother and her child.

This study had an open cohort design, with rolling recruitment and follow up of pregnant women for a period of two years. The study was conducted from March 2014 to March 2016 in three Districts (Woliso, Tiro-Afeta and Gomma) in the South Western part of Ethiopia. A total of 4680 pregnant women were recruited between 12 to 32 weeks of gestation and followed up until 12 months postpartum. Data was collected once during pregnancy for all women (twice for those in the first trimester at recruitment), at birth, and then every three months until the child was 12 months old. Data collection was conducted by trained nurses electronically using Open Data Kit (ODK) software on handheld tablets and submitted to a secured server via an internet connection. Ethical clearance was obtained from Jimma University ethical review board. Informed written consent was obtained from all individual participants included in the study. All interviews were conducted in private and confidentiality was ensured for each study participants.

\section{Measurements \\ Depressive symptoms}

Prenatal depressive symptoms were assessed using the patient health questionnaire (PHQ-9). The PHQ-9 is a 9-item self-administered questionnaire designed to evaluate the presence of depressive symptoms during the prior two weeks [20]. Each of the nine items can be scored from 0 (not at all) to 3 (nearly every day). Thus, total score can range from 0 (absence of depressive symptoms) to 27 (most severe depressive symptoms). This instrument had 
been validated for Afaan Oromo Language in a similar population prior to the commencement of the ENGINE birth cohort study and possessed good psychometric properties. A PHQ-9 score of 8 or above was taken as a cut off to define prenatal symptomatology [21].

\section{Nutritional status}

Mid upper arm circumference (MUAC) was used to estimate maternal nutritional status. It was measured three times at each visit at the midpoint between the tip of the shoulder and the elbow of the left upper arm using inelastic adult MUAC tape. The average of three MUAC measurements was calculated and then categorized as normal or low MUAC. A MUAC of less than $23 \mathrm{~cm}$ was considered to be a sign of poor nutrition [22].

\section{Anaemia}

Haemoglobin concentration was measured using HemoCue ${ }^{\bullet}$ $\mathrm{Hb} 301$ system for mobile screening. One drop of blood was collected in a HemoCue microcuvette and the haemoglobin concentration was read directly in the field. Anaemia was defined as haemoglobin concentration $<11 \mathrm{~g} / \mathrm{dl}$ after adjusted for altitude and pregnancy to get the sea level value according to the method described by Cohen and Hass [23].

\section{Household food insecurity}

The household food insecurity was measured using the Household Food Insecurity Access Scale [24]. The index women were asked nine questions (yes/no) to determine if anyone in their household had experienced problems of food access over four weeks preceding the interview. An affirmative response to any of the nine questions was followed by a question to determine how often the condition happened: rarely (1-2 times), sometimes (3-10 times), and often ( $>10$ times). Responses were coded as $0=$ never (i.e., no experience), $1=$ rarely, $2=$ sometimes, or $3=$ often. Household food insecurity was categorized into four severity levels: food secure, mildly food insecure, moderately food insecure, and severely food insecure as per the algorithm described by Coates et al. [24].

\section{Socio-demographic factors}

Educational status of the index mother was dichotomized as above primary school and primary or below for analysis purpose. Marital status was dichotomized into married (married monogamous and married polygamous) and unmarried (single, widowed, divorced, and separated). Religion was categorized into three as Protestant and Catholic, Muslim and Orthodox (only 3 respondents were follower of traditional religion or pagan and hence were not separately analyzed).

\section{Obstetric related risk factors}

Gravidity, gestational age, acute illnesses in the past two weeks, place of previous delivery and history of previous antenatal care visits; previous child death and spontaneous abortion were considered obstetric-related risk factors. Gravidity was categorized into primi-gravida (first pregnancy), multi-gravida (2-4 pregnancy experience) and grand-multi-gravida (five or more than five pregnancy experiences). While gestational age was categorized into three as first trimester (up to 12 weeks of gestation), second trimester (13-26 weeks of gestation) and third trimester (above 26 weeks of gestation).

\section{Intimate partner violence (IPV)}

A screening tool called HITS (Hurt, Insult, Threaten and Scream) was applied to assess intimate partner violence. This screening tool measures the emotional (psychological) aspects of intimate partner violence. The scale has four items and each item was scored on a scale of 1 (never) to 5 (frequently) and later the sum score was computed. A total score of $>10$ is suggestive of IPV [25].

\section{Maternal social support}

Maternal Social support was measured using the Maternity Social Support Scale (MSSS) developed by Webster and colleagues [26]. The scale contains six items. Each item has measured on a five-point Likert scale and a total score of 30 was possible. We classified social support into two categories based on the mean score; below mean and mean or above mean score.

\section{Data analysis}

The data was analyzed using SPSS version 20. Bivariate and multivariate logistic regression analyses were computed to examine the relationship between the independent variables and prenatal depressive symptoms. The binary form of the dependent variable was coded as "1" for prenatal depressive symptoms (PHQ-9 score $>=8$ ) and " 0 " for the absence (PHQ-9 score $<8$ ). First binary logistic regression analyses were conducted between each individual independent variable and prenatal depressive symptoms. The findings were reported using unadjusted Odds Ratios (OR) and its 95\% confidence interval (CI).

Then a full model including the nutritional (household food insecurity, anaemia, MUAC, fasting, nutrition related knowledge) socio-demographic (age, religion, marital status, family size and wealth index) and other confounders (obstetric factors, acute illnesses, social support, chat chewing practices and intimate partner violence) were fitted using a multivariate binary logistics regression to identify the independent predictors of prenatal depressive symptoms. Adjusted odds ratios (OR) and their 95\% CI were presented as indicators of strength of association. A 
$p$-value of 0.05 or less was used to determine the cut-off points for statistical significance.

\section{Results}

\section{Characteristics of study participants}

All recruited 4680 pregnant women between March 2014 and March 2016 were included in the final analysis. The median age of study participants was 26 years [inter-quartile range (IQR) 22, 30]. More than half of the pregnant women $(55.2 \%)$ were illiterate and only $241(5.1 \%)$ of the respondents had completed secondary education or higher. Just over two-third (67.3\%) of the respondents were Muslim and $97.7 \%$ were married. Participants' characteristics are presented in Table 1.

\section{Prevalence of prenatal depressive symptoms}

A total of 506 pregnant women had a PHQ-9 score $\geq 8$, yielding a crude depressive symptom prevalence rate of $10.81 \%$ (95\% CI: 9.92-11.70). The prevalence of depressed mood in pregnant women is depicted in Table 2 . The prevalence was higher among pregnant women age above 35 years (11.8\% versus $8.6 \%$ for younger women), unmarried (26.9\% versus $10.4 \%$ for married) and illiterate (11.4\% versus $5.0 \%$ for secondary school and above). Nearly $13 \%$ of Muslim pregnant women were in depressed mood compared to $6.7 \%$ for Orthodox and 6.1\% for Protestants and Catholic Christians. The prevalence of prenatal depressive symptoms increased with household food insecurity severity; $34.4 \%$ of mothers in severely food insecure households were suffering from depressed mood compared to $4.8 \%$ in food secure households $(p<0.001)$. Moreover, the prevalence was higher among anaemic $(14.2 \%$ versus 9.5\% for without anaemia) and under-nourished (12.4\% versus $9.7 \%$ for well-nourished, $p=0.005$ ) pregnant women. The depressive symptoms prevalence increased with gestational age which is $8.7 \%, 10.2 \%$ and $12.0 \%$ $(p=0.039)$ for first, second and third trimester respectively. The severity of the depressed mood was also increased with gestational age with mean values of $2.98( \pm 3.05), 3.03( \pm 3.50)$ and $3.26( \pm 3.61)$ for the first, second and third trimester respectively. Prenatal depressive symptomatology was more prevalent among mothers who encountered intimate partner violence $(29.7 \%$ versus 9.8\% for mothers with no IPV experience).

\section{Socio-demographic factors}

Prenatal depressive symptoms was significantly associated with marital status $(p<0.001)$. Unmarried pregnant women were 2.65 times more likely to develop depressive symptoms than their married counterparts $(\mathrm{AOR}=2.65$; 95\%CI: 1.59-4.44). Pregnant women in households with more than five family size are 1.36 times $(\mathrm{AOR}=1.36$; 95\%CI: 1.08-1.71) more at risk of depressive symptoms than those living in small family size households. Similarly, geographic location was important with women living in some districts being more likely to exhibit depressive symptoms. Pregnant women in Gomma and Tiro-Afeta districts faced 3.04 times (AOR $=3.04 ; 95 \% \mathrm{CI}: 2.04-4.53)$ and 2.02 times $(\mathrm{AOR}=2.02$; 95\%CI: 1.34-3.05) higher risk of depressive symptoms than those living in Woliso district. None of the remaining socio-demographic variables shown in Table 2 were associated with an increased prevalence of major depressive symptoms (Table 2).

\section{Nutrition related factors}

After adjusting for confounding variables, women with moderate and severe household food insecurity had 1.74 $(\mathrm{AOR}=1.74 ; 95 \% \mathrm{CI}: 1.31-2.32)$ and 7.90 (AOR 7.90; 95\% CI: 5.87-10.62) times higher risk of prenatal depressive symptoms respectively than women who were living in food secure households. Similarly, anaemic pregnant women were at higher risk of prenatal depression than those with normal haemoglobin concentration (AOR = 1.30; 95\% CI: 1.04-1.61). Examining the crude odds ratios, we found that prenatal depressive symptoms was positively associated with both undernutrition assessed by low MUAC $(\mathrm{AOR}=1.31 ; 95 \% \mathrm{CI}: 1.09-1.57)$ and chat chewing $(\mathrm{AOR}=1.58 ; 95 \% \mathrm{CI}: 1.26-2.00)$. However, this relationship disappeared when adjusted for all other variables in the final model (Table 2).

\section{Intimate partner violence and maternal social support}

As shown in Table 2, depressive symptomatology was more likely among participants who encountered higher intimate partner violence (AOR $=3.08$; 95\%CI: $2.23-4.25$ ) and poor social support from spouse, families and friends $(\mathrm{AOR}=1.63 ; 95 \% \mathrm{CI}: 1.31-2.02)$.

\section{Discussion}

The key contribution of this paper is to show the prevalence of prenatal depressive symptoms and its association with nutrition related factors, intimate partner violence and social support in rural Ethiopia. This finding has important implications, particularly in Ethiopia, where the burden of mental health diseases and intimate partner violence are high, resource allocation towards mental health care is poor with four psychiatrists per $10,000,000$ population [27], inadequate nutritional status in pregnancy is still a considerable public health burden and both nutrition and intimate partner violence are modifiable risk factors.

The relationship between IPV, depression and food insecurity are all bidirectional and social support plays a buffering and protective role in this link. Depression is the most common mental health consequences of IPV $[28,29]$. Previous studies indicated that women who experience IPV have about four times greater risk of depression than women who do not experience IPV. On 
Table 1 Characteristics of the study participants, Ethiopia, 2016

\begin{tabular}{|c|c|c|c|}
\hline Variables & & Number & Percent \\
\hline \multirow[t]{4}{*}{ Age } & Less than 25 years & 1615 & 34.5 \\
\hline & $25-35$ years & 2831 & 60.5 \\
\hline & Above 35 years & 234 & 5.0 \\
\hline & Median (IQR) & $26(22-30)$ & \\
\hline \multirow[t]{4}{*}{ Religion } & Muslim & 3148 & 67.3 \\
\hline & Orthodox & 1057 & 22.6 \\
\hline & Protestant \& Catholic & 472 & 10.1 \\
\hline & Missing & 3 & 0.1 \\
\hline \multirow[t]{2}{*}{ Marital status } & Married & 4572 & 97.7 \\
\hline & Unmarried & 108 & 2.3 \\
\hline \multirow[t]{5}{*}{ Education } & Illiterate & 2585 & 55.2 \\
\hline & Primary school & 1491 & 31.9 \\
\hline & Junior secondary school & 363 & 7.8 \\
\hline & Secondary and above & 241 & 5.1 \\
\hline & Median (IQR) & $0(0-4)$ & \\
\hline \multirow[t]{3}{*}{ Family size } & Less than five & 2216 & 47.4 \\
\hline & Five or more & 2464 & 52.6 \\
\hline & Median (IQR) & $5(3-6)$ & \\
\hline \multirow[t]{5}{*}{ Wealth quintile } & Lowest & 928 & 19.8 \\
\hline & Second & 957 & 20.4 \\
\hline & Middle & 863 & 18.4 \\
\hline & Fourth & 986 & 21.1 \\
\hline & Highest & 934 & 20.0 \\
\hline \multirow[t]{4}{*}{ Household Food Insecurity } & Secure & 1600 & 34.2) \\
\hline & Mildly insecure & 600 & 12.8 \\
\hline & Moderately insecure & 1846 & 39.4 \\
\hline & Severely insecure & 634 & 13.5 \\
\hline \multirow[t]{2}{*}{ Fasting } & Yes & 2428 & 51.9 \\
\hline & No & 2252 & 48.1 \\
\hline \multirow[t]{2}{*}{ Anaemia } & Greater or equal to $11 \mathrm{~g} / \mathrm{dl}$ & 3409 & 72.84 \\
\hline & Less than $11 \mathrm{~g} / \mathrm{dl}$ & 1271 & 27.2 \\
\hline \multirow[t]{3}{*}{ Mid-upper Arm Circumference (MUAC) } & Greater or equal to $23 \mathrm{~cm}$ & 2771 & 59.2 \\
\hline & Less than $23 \mathrm{~cm}$ & 1909 & 40.8 \\
\hline & Median (IQR) & $23.30(22.07-24.57)$ & \\
\hline \multirow[t]{2}{*}{ Chat chewing } & Yes & 690 & 14.7 \\
\hline & No & 3990 & 85.3 \\
\hline \multirow[t]{2}{*}{ Nutrition related knowledge } & Yes & 315 & 6.7 \\
\hline & No & 4365 & 93.3 \\
\hline \multirow[t]{3}{*}{ Antenatal care (previous pregnancy) } & No ANC & 1626 & 34.7 \\
\hline & One to three times & 1924 & 41.1 \\
\hline & Greater than four visits & 1859 & 39.7 \\
\hline \multirow[t]{3}{*}{ Gravidity } & Primi-gravida & 608 & 13.0 \\
\hline & Multigravida & 1924 & 41.1 \\
\hline & Grand multigravida & 2148 & 45.9 \\
\hline
\end{tabular}


Table 1 Characteristics of the study participants, Ethiopia, 2016 (Continued)

\begin{tabular}{|c|c|c|c|}
\hline Variables & & Number & Percent \\
\hline \multirow[t]{3}{*}{ Gestational age } & First trimester & 164 & 3.5 \\
\hline & Second trimester & 2869 & 61.3 \\
\hline & Third trimester & 1647 & 35.2 \\
\hline \multirow[t]{2}{*}{ History of child death } & Yes & 1214 & 25.9 \\
\hline & No & 3466 & 74.1 \\
\hline \multirow[t]{2}{*}{ Previous spontaneous abortion } & Yes & 539 & 11.5 \\
\hline & No & 4141 & 88.5 \\
\hline \multirow[t]{2}{*}{ Acute illness } & Yes & 1203 & 25.7 \\
\hline & No & 3477 & 74.3 \\
\hline \multirow[t]{3}{*}{ Social participation } & Yes & 2886 & 61.7 \\
\hline & No & 1794 & 38.3 \\
\hline & Median (IQR) & $1.0(0-1.0)$ & \\
\hline \multirow[t]{2}{*}{ Maternal social support } & Good support & 2485 & 53.1 \\
\hline & Poor support & 2195 & 46.9 \\
\hline \multirow[t]{2}{*}{ Intimate partner violence } & Yes & 232 & 5.0 \\
\hline & No & 4448 & 95.0 \\
\hline
\end{tabular}

the other hand, depression is associated with the use of hostility, insult, and threat in marital interactions $[30,31]$. When we see the pathway between IPV and household food insecurity, previous research demonstrated that it is mediated by depression [32].

Poverty is one of the key contributors to intimate partner violence [33]. Since poverty is inherently stressful, it has been argued that intimate partner violence may result from stress and that poorer men have fewer resources to reduce stress. Poverty as it impairs purchasing power, results in household food insecurity. IPV may affect the couple's capacity to organize the home environment and manage the resources available in order to guarantee the food and nutrition security of the family. Looking this link from household food insecurity side, a broader anthropological conceptualization of food insecurity posits that acute or chronic exposure to periods of food uncertainty can influence mental and physical health outcomes. Social support plays a buffering role for both depressive symptoms and IPV. Social support from family or friends buffers the effects of environmental stressors such as IPV and poverty and could decrease individual's vulnerability to depression [34].

Consistent with previous studies in low, middle and high income countries, this study revealed that household food insecurity is strong predictor of prenatal depressive symptoms [12, 35-38]. Food insecurity by itself is a stressful life event, and the occurrence of stressful events was shown to affect the hypothalamic-pituitary-adrenocortical (HPA) axis. It is also known that hypothalamic dysfunction was linked to the onset and recurrence of depression [39].
Moreover, previous studies indicated that food insecurity was linked to specific nutrient deficiencies, which were also associated with depressive symptoms [16, 40]. These studies showed that food insecurity influences prenatal depression through deficiencies in energy, vitamin B12, Selenium or folic acid. Yet, another study also indicated that low-income women with depressive symptoms and life stressors represent an at-risk group for low diet quality during pregnancy and hence the link between depression and nutrient deficiencies is bidirectional [41]. Using nationally representative data and a number of different modeling approaches, Noonan and colleagues found robust evidence that maternal depression has adverse effects on household food insecurity [42]. Hence, the association between depression and food insecurity is also bidirectional.

In this study, pregnant women with depressive symptoms had lower haemoglobin levels than women without depressive symptoms. In agreement with our findings, previous observational studies generally established that anaemia is associated with depression [13, 43]. However, a placebo and high-iron diet controlled supplementation trial among female participants in high income countries found no association between depression and anaemia [44].

The relationship and direction of the relationship between depression and maternal anaemia remains unclear and still needs further investigation. However, there are different hypotheses about the mechanisms linking anaemia with depression. Iron is a co-factor in synthesis of tyrosine and tryptophan. Tyrosine and tryptophan are precursors for the neurotransmitters dopamine, norepinephrine and serotonin [45]. The traditional monoamine 
Table 2 Variables associated with prenatal depressive symptoms, Ethiopia, 2016

\begin{tabular}{|c|c|c|c|c|c|c|}
\hline Variables & & $\begin{array}{l}\text { Depressive Symptoms } \\
\text { Number (\%) }\end{array}$ & $\begin{array}{l}\text { Unadjusted OR } \\
(95 \% \mathrm{Cl})\end{array}$ & $p$-value & Adjusted OR (95\%Cl) & $p$-value \\
\hline \multirow[t]{3}{*}{ Age } & Less than 25 years & $139(8.6)$ & $0.59(0.39-0.90)$ & 0.01 & $0.77(0.47-1.26)$ & 0.294 \\
\hline & $25-35$ years & $335(11.8)$ & $0.85(0.57-1.25)$ & 0.41 & $0.85(0.55-1.32)$ & 0.474 \\
\hline & Above 35 years & $32(13.7)$ & 1.0 & & 1.0 & \\
\hline \multirow[t]{3}{*}{ Religion } & Orthodox & $71(6.7)$ & $0.91(0.58-1.42)$ & 0.68 & $0.80(0.54-1.19)$ & 0.272 \\
\hline & Protestant \& Catholic & $29(6.1)$ & $2.05(1.58-2.67)$ & $<0.001$ & $0.85(0.50-1.45)$ & 0.557 \\
\hline & Muslim & $405(12.9)$ & 1.0 & & 1.0 & \\
\hline \multirow[t]{2}{*}{ Marital status } & Married & $477(10.4)$ & 1.0 & & 1.0 & \\
\hline & Unmarried & 29 (26.9) & $3.15(2.04-4.87)$ & $<0.001$ & 2.65 (1.59-4.44) & $<0.001$ \\
\hline \multirow[t]{2}{*}{ Education } & Primary or below & $465(11.4)$ & $1.77(1.27-2.46)$ & $<0.001$ & $1.07(0.74-1.56)$ & 0.707 \\
\hline & Above primary & $41(6.8)$ & 1.0 & & 1.0 & \\
\hline \multirow[t]{2}{*}{ Family size } & Less than five & $198(8.9)$ & 1.0 & & 1.0 & \\
\hline & Five or more & $308(12.5)$ & $1.46(1.21-1.76)$ & $<0.001$ & $1.36(1.08-1.71)$ & 0.010 \\
\hline \multirow[t]{5}{*}{ Wealth index } & Lowest & $90(9.7)$ & $0.81(0.60-1.08)$ & 0.148 & & \\
\hline & Second & $125(13.1)$ & $1.13(0.86-1.48)$ & 0.397 & & \\
\hline & Middle & $78(9.0)$ & $0.74(0.55-1.01)$ & 0.059 & & \\
\hline & Fourth & $103(10.4)$ & $0.87(0.66-1.16)$ & 0.354 & & \\
\hline & Highest & $110(11.8)$ & 1.0 & & & \\
\hline \multirow[t]{3}{*}{ Address } & Gomma & $209(13.4)$ & $2.26(1.76-2.90)$ & $<0.001$ & $3.04(2.04-4.53)$ & $<0.001$ \\
\hline & Tiro-Afeta & $197(12.6)$ & $2.11(1.64-2.71)$ & $<0.001$ & $2.02(1.34-3.05)$ & 0.001 \\
\hline & Woliso & $100(6.4)$ & 1.0 & & 1.0 & \\
\hline \multirow[t]{4}{*}{ Household Food Insecurity } & Secure & $76(4.8)$ & 1.0 & & 1.0 & \\
\hline & Mildly insecure & $29(4.8)$ & $1.02(0.66-1.56)$ & 0.309 & $0.84(0.54-1.31)$ & 0.445 \\
\hline & Moderately insecure & $183(9.9)$ & $2.21(1.67-2.91)$ & 0.001 & $1.74(1.31-2.32)$ & $<0.001$ \\
\hline & Severely insecure & $218(34.4)$ & $10.51(7.92-13.94)$ & $<0.001$ & $7.90(5.87-10.62)$ & $<0.001$ \\
\hline \multirow[t]{2}{*}{ Fasting } & Yes & $256(10.5)$ & 1.0 & & & \\
\hline & No & $250(11.1)$ & $1.06(0.88-1.27)$ & 0.539 & & \\
\hline \multirow{2}{*}{$\begin{array}{l}\text { Haemoglobin } \\
\text { Concentration }\end{array}$} & $11 \mathrm{~g} / \mathrm{dl}$ or more & $325(9.5)$ & 1.0 & & 1.0 & \\
\hline & Less than $11 \mathrm{~g} / \mathrm{dl}$ & $181(14.2)$ & $1.58(1.30-1.91)$ & $<0.001$ & $1.30(1.04-1.61)$ & 0.019 \\
\hline \multirow{2}{*}{$\begin{array}{l}\text { Mid-upper Arm Circumference } \\
\text { (MUAC) }\end{array}$} & Greater or equal to $23 \mathrm{~cm}$ & $270(9.7)$ & 1.0 & & 1.0 & \\
\hline & Less than $23 \mathrm{~cm}$ & $236(12.4)$ & $1.31(1.09-1.57)$ & 0.005 & $0.96(0.78-1.18)$ & 0.692 \\
\hline \multirow[t]{2}{*}{ Chat chewing } & Yes & $104(15.1)$ & $1.58(1.26-2.00)$ & $<0.001$ & $0.94(0.72-1.23)$ & 0.638 \\
\hline & No & $402(10.1)$ & 1.0 & & 1.0 & \\
\hline \multirow[t]{2}{*}{ Nutrition Related knowledge } & Yes & $43(13.7)$ & 1.0 & & & \\
\hline & No & $463(10.6)$ & $0.75(0.54-1.05)$ & 0.094 & & \\
\hline \multirow[t]{2}{*}{ Maternal social support } & Good support & $185(7.4)$ & 1.0 & & 1.0 & $<0.001$ \\
\hline & Poor support & $321(14.6)$ & $2.13(1.76-2.58)$ & $<0.001$ & $1.63(1.31-2.02)$ & \\
\hline \multirow[t]{2}{*}{ Intimate partner violence } & Yes & $69(29.7)$ & $3.38(2.59-4.42)$ & $<0.001$ & $3.08(2.23-4.25)$ & $<0.001$ \\
\hline & No & $437(9.8)$ & 1.0 & & 1.0 & \\
\hline
\end{tabular}

hypothesis of depression speculates that low dopamine, norepinephrine, and serotonin concentrations may result in depression [46]. In addition, iron is a cofactor for the reaction leading to the production and secretion of glutamate [47]. The glutamate hypothesis of depression has posited that dysregulation of the glutamatergic system results in depression [48].

In congruence with other previous studies, we found a statistically significant association between intimate partner violence and prenatal depressive symptoms [14, 15, 49]. 
Because of fear of stigmatization, battered women often experience feelings of shame, isolation and entrapment and did not communicate openly to others that violence occurred to them by their spouses [50]. This results in lack of support from friends and families and rather leads to more depression.

Respondents with prenatal depressive symptoms reported poorer maternal social support compared to their counterparts. Our finding is consistent with the suggestion that social support may safeguard the adverse effects of prenatal psychological distress on birth outcomes [51, 52]. The buffering hypothesis of social support postulated that the potential pathogenic effect of stressful events is reduced when support is accessible [53].

The prevalence of depressive symptoms during pregnancy in our study was lower compared to previous prevalence reports in Ethiopia [4-7, 54]. The relatively lower prevalence in our study probably reflects the fact that this is a population based study while the prior studies were health facility based. It could be postulated that the difference in rates could be due to different population sub-groups, for example in the health facility based studies, respondents are likely to be medical patients who may be reporting somatic symptoms (e.g. fatigue and anorexia) that might be confounded by the underlying condition that the patients are seeking care. Spitzer et al. [55] recommended that tools with questions about appetite, fatigue, or sleep (e.g., PHQ-9) must be interpreted cautiously, as impairment might reflect the physical effect of pregnancy rather than depressive symptoms.

We found a statistically significant difference in prenatal depressive symptoms prevalence among the three study districts with the lowest prevalence found in Woliso. Worldwide estimates of depressive symptoms vary widely between studies and settings, discrepancies being attributable to real differences between countries but also to the method of assessment [56]. Previous studies in Ethiopia reported a differential prenatal depressive symptoms prevalence by study sites [4-7]. Each of these studies used different tools to screen depressive symptoms.

Adjusting for relevant confounding variables, we found that marital status, geographical location, family size, household food insecurity and anaemia were identified as predictors of prenatal depressive symptoms. The association between marital status and prenatal depressed mood is consistent with a number of studies in low, middle and high income countries where they found higher rates of mental distress in the widowed, separated and divorced women in comparison with married women [57, 58]. However, other general population studies reported no association $[59,60]$.

The main strength of this study lies in access to community based data to describe prevalence and associated risk factors of depressive symptoms during pregnancy.
This study is also based on large sample size and huge response rate; a very thorough description of the population with a big number of questionnaires on different socio-demographic, nutritional and other clinical risk factors. Being a cross-sectional analysis, the usual restrictions inherent to cross-sectional and observational studies apply here; no information about causality. An additional limitation of this study is that we used one month recall on the food-insecurity measure, but a two weeks recall on the measure of depressive symptoms, which raises concerns over the reported associations.

\section{Conclusions}

Prenatal depressive symptomatology is quite common during pregnancy. Socio-demographic factors such as marital status, family size and geographical location are associated with an increased prevalence of prenatal depressive symptoms. Similarly, nutrition related factors such as household food insecurity and anaemia are associated with prenatal depression. While social support from friends, families and spouse during pregnancy are protective, intimate partner violence augments prenatal depression.

The implications of our study for practice are to emphasize the need for targeted screening for intimate partner violence and depressive symptoms during pregnancy and to link cases to health facilities where treatment is available. In this regard we recommend the Ethiopian Ministry of Health to integrate screening of depressive symptoms and intimate partner violence in routine antenatal care services. Policies aimed at reducing household food insecurity, maternal anaemia, intimate partner violence and promoting maternal social support are likely to have a significant public health impact in preventing prenatal depression. Organizing a mental health team, including health extension workers, in antenatal services to screen and treat prenatal depression together with the aforementioned risk factors during pregnancy might prevent or ameliorate prenatal depression.

\section{Abbreviations \\ Cl: Confidence Interval; HITS: Hurt, Insult, Threaten and Scream; IPV: Intimate Partner Violence; LMIC: Lower-Middle-Income Countries; MSS: Maternal Social support; MDD: Major depressive disorder; MUAC: Mid upper arm circumference; OR: Odds Ratio; PHQ-9: Patient health questionnaire-9; PUFA: Polyunsaturated fatty acids; SPSS: Statistical Package for the Social Sciences; USAID: United States Agency for International Development}

\section{Acknowledgements}

We would like to thank the women who volunteered to participate in this study.

\section{Funding}

This research is made possible by the support of the American people through the United States Agency for International Development (USAID) under Agreement No. AID-663-A-11-00017. The contents of this document are the sole responsibility of the researchers \& do not necessarily reflect the views of USAID or the United States Government. 


\section{Availability of data and materials}

The data that support the findings of this study are available from Tufts and Jimma Universities but restrictions apply to the availability of these data, which were used under license for the current study, and so are not publicly available. Data are however available from the authors upon reasonable request and with permission of Tufts and Jimma Universities.

\section{Authors' contributions}

YK designed/implemented the study, analyzed the data and drafted the manuscript; SG \& TB designed/implemented the study and critically reviewed the final version of the manuscript; VS, EK, MEL \& HKB assisted data analysis and critically reviewed the manuscript. All authors read and approved the final manuscript.

\section{Ethics approval and consent to participate}

The study was conducted in accordance with the WHO's ethical and safety recommendations for research on domestic violence against women [61]. The main principals to justify this research were also fulfilled according to the World Medical Association Declaration of Helsinki [62]. During data collection, all measures were taken to ensure that women could get support if it was deemed necessary. Study participants who were screened positive for depressive symptoms or IPV were referred to a nearby health facility for possible social and medical support. Ethical clearance was obtained from Jimma University ethical review board.

Informed written consent was obtained from all individual participants included in the study. All interviews were conducted in private and confidentiality was ensured for each study participants. Study participants who were screened suffering from IPV were referred to Jimma University Hospital for social and psychological care.

\section{Consent for publication}

Not applicable.

\section{Competing interests}

The authors declare that they have no competing interests.

\section{Publisher's Note}

Springer Nature remains neutral with regard to jurisdictional claims in published maps and institutional affiliations.

\section{Author details \\ ${ }^{1}$ Institute of Biological Chemistry and Nutrition (140a), University of Hohenheim, Stuttgart, Germany. ${ }^{2}$ Food Security Center, University of Hohenheim, Stuttgart, Germany. ${ }^{3}$ Department of Population and Family Health, College of Health Sciences, Jimma University, Jimma, Ethiopia. ${ }^{4} T$ ufts University, Freidman School of Nutrition Science and Policy, Boston, USA. ${ }^{5}$ Department of Gynecology, Faculty of Medicine, Martin-Luther University, Halle, Germany. ${ }^{6}$ Institute of Medical Epidemiology, Biostatistics, and Informatics, Faculty of Medicine, Martin-Luther University, Halle, Germany.}

\section{Received: 2 March 2017 Accepted: 6 September 2018}

\section{Published online: 15 September 2018}

\section{References}

1. Gilbert BJ, Patel V, Farmer PE, Lu C. Assessing development assistance for mental health in developing countries: 2007-2013. PLoS Med. 2015;12: e1001834. https://doi.org/10.1371/journal.pmed.1001834.

2. Gelaye B, Rondon MB, Araya R, Williams MA. Epidemiology of maternal depression, risk factors, and child outcomes in low-income and middleincome countries. Lancet Psychiatry. 2016;3:973-82. https://doi.org/10.1016/ S2215-0366(16)30284-X.

3. Wachs TD, Black MM, Engle PL. Maternal depression: a global threat to Children's health, development, and behavior and to human rights. Child Dev Perspect. 2009;3:51-9. https://doi.org/10.1111/j.1750-8606.2008.00077.x.

4. Hanlon C, Medhin G, Alem A, Tesfaye F, Lakew Z, Worku B, et al. Impact of antenatal common mental disorders upon perinatal outcomes in Ethiopia: the P-MaMiE population-based cohort study. Trop Med Int Health TM $1 \mathrm{H}$. 2009;14:156-66.

5. Ayele T, Azale T, Alemu K, Abdissa Z, Mulat H, Fekadu A. Prevalence and associated factors of antenatal depression among women attending antenatal Care Service at Gondar University Hospital, Northwest Ethiopia. PLoS One. 2016;11:e0155125. https://doi.org/10.1371/journal.pone.0155125.

6. Biratu A, Haile D. Prevalence of antenatal depression and associated factors among pregnant women in Addis Ababa, Ethiopia: a cross-sectional study. Reprod Health. 2015;12. https://doi.org/10.1186/s12978-015-0092-x.

7. Tefera TB, Erena AN, Kuti KA, Hussen MA. Perinatal depression and associated factors among reproductive aged group women at Goba and robe town of bale zone, Oromia region, south East Ethiopia. Matern Health Neonatol Perinatol. 2015;1. https://doi.org/10.1186/s40748-015-0013-6.

8. Rahman A, Creed F. Outcome of prenatal depression and risk factors associated with persistence in the first postnatal year: prospective study from Rawalpindi, Pakistan. J Affect Disord. 2007;100:115-21.

9. Hartley M, Tomlinson M, Greco E, Comulada WC, Stewart J, le Roux I, et al. Depressed mood in pregnancy: prevalence and correlates in two Cape Town peri-urban settlements. Reprod Health. 2011;8. https://doi.org/10.1186/1742-4755-8-9.

10. Brody BD, Chaudhry SK, Penzner JB, Meltzer EC, Dubin M. A woman with major depression with psychotic features requesting a termination of pregnancy. Am J Psychiatry. 2016;173:12-5. https://doi.org/10.1176/appi.ajp.2015.15030380.

11. Rahman A, Patel V, Maselko J, Kirkwood B. The neglected " $m$ " in $\mathrm{MCH}$ programmes - why mental health of mothers is important for child nutrition: The neglected " $\mathrm{m}$ " in MCH programmes. Trop Med Int Health. 2008;13:579-83. https://doi.org/10.1111/j.1365-3156.2008.02036.x.

12. Jebena $M G$, Taha M, Nakajima M, Lemieux A, Lemessa F, Hoffman $R$, et al. Household food insecurity and mental distress among pregnant women in southwestern Ethiopia: a cross sectional study design. BMC Pregnancy Childbirth. 2015;15. https://doi.org/10.1186/s12884-015-0699-5.

13. Khambalia AZ, Collins CE, Roberts CL, Morris JM, Powell KL, Tasevski V, et al. Iron deficiency in early pregnancy using serum ferritin and soluble transferrin receptor concentrations are associated with pregnancy and birth outcomes. Eur J Clin Nutr. 2016;70:358-63. https://doi.org/10.1038/ejcn.2015.157.

14. Rodríguez MA, Valentine J, Ahmed SR, Eisenman DP, Sumner LA, Heilemann $M V$, et al. Intimate partner violence and maternal depression during the perinatal period: a longitudinal investigation of Latinas. Violence Women. 2010;16:543-59. https://doi.org/10.1177/1077801210366959.

15. Van Parys A-S, Deschepper E, Michielsen K, Galle A, Roelens K, Temmerman $M$, et al. Intimate partner violence and psychosocial health, a cross-sectional study in a pregnant population. BMC Pregnancy Childbirth. 2015;15. https://doi.org/10.1186/s12884-015-0710-1.

16. Wani AL, Bhat SA, Ara A. Omega-3 fatty acids and the treatment of depression: a review of scientific evidence. Integr Med Res. 2015;4:132-41. https://doi.org/10.1016/j.imr.2015.07.003.

17. Fontein-Kuipers $Y$, van Limbeek $E$, Ausems M, de Vries $R$, Nieuwenhuijze M. Responding to maternal distress: from needs assessment to effective intervention. Int J Public Health. 2016. https://doi.org/10.1007/s00038-016-0910-0.

18. Sparling TM, Henschke N, Nesbitt RC, Gabrysch S. The role of diet and nutritional supplementation in perinatal depression: a systematic review: review of dietary intake and perinatal depression. Matern Child Nutr. 2017;13. https://doi.org/10.1111/mcn. 12235 .

19. Semahegn A, Mengistie B. Domestic violence against women and associated factors in Ethiopia; systematic review. Reprod Health. 2015;12. https://doi.org/10.1186/s12978-015-0072-1.

20. Kroenke K, Spitzer RL, Williams JBW. The PHQ-9: validity of a brief depression severity measure. J Gen Intern Med. 2001;16:606-13. https://doi.org/10.1046/j.1525-1497.2001.016009606.x.

21. Woldetensay YK, Belachew T, Tesfaye M, Spielman K, Biesalski HK, Kantelhardt EJ, et al. Validation of the patient health questionnaire (PHQ-9) as a screening tool for depression in pregnant women: Afaan Oromo version. PLoS One. 2018;13:e0191782. https://doi.org/10.1371/journal.pone.0191782.

22. Ververs M, Antierens A, Sackl A, Staderini N, Captier V. Which anthropometric indicators identify a pregnant woman as acutely malnourished and predict adverse birth outcomes in the humanitarian context? PLoS Curr. 2013. https://doi.org/10.1371/currents.dis. 54a8b618c1bc031ea140e3f2934599c8.

23. Nestel P. Adjusting Hemoglobin Values in Program Surveys. 2002. https://dokumen.tips/documents/adjusting-hemoglobin-values-inprogram-hemoglobin-values-in-programsurveys-html.

24. Coates J, Swindale A, Bilinsky P. Household food insecurity access scale (HFIAS) for measurement of food access: Indicator guide. Washington, D.C: 2007. http://www.fao.org/fileadmin/user_upload/eufao-fsi4dm/doc-training/hfias.pdf. 
25. Deshpande NA, Lewis-O'Connor A. Screening for intimate partner violence during pregnancy. Rev Obstet Gynecol. 2013;6:141-8.

26. Mercer RT, Ferketich SL. Stress and social support as predictors of anxiety and depression during pregnancy. ANS Adv Nurs Sci. 1988;10:26-39.

27. WHO. Mental Health Atlas 2011-Ethiopia. 2011.

28. Schumacher JA, Feldbau-Kohn S, Smith Slep AM, Heyman RE. Risk factors for male-to-female partner physical abuse. Aggress Violent Behav. 2001;6:281352. https://doi.org/10.1016/S1359-1789(00)00027-6.

29. Stith SM, Smith DB, Penn CE, Ward DB, Tritt D. Intimate partner physical abuse perpetration and victimization risk factors: a meta-analytic review. Aggress Violent Behav. 2004;10:65-98. https://doi.org/10.1016/j.avb.2003.09.001.

30. Coyne JC, Thompson R, Palmer SC. Marital quality, coping with conflict, marital complaints, and affection in couples with a depressed wife. J Fam Psychol. 2002;16:26-37.

31. Du Rocher Schudlich TD, Papp LM, Cummings EM. Relations of husbands' and wives' dysphoria to marital conflict resolution strategies. J Fam Psychol. 2004;18:171-83. https://doi.org/10.1037/0893-3200.18.1.171.

32. Hernandez DC, Marshall A, Mineo C. Maternal depression mediates the association between intimate partner violence and food insecurity. J Women's Health. 2014;23:29-37. https://doi.org/10.1089/jwh.2012.4224.

33. Jewkes R. Intimate partner violence: causes and prevention. Lancet. 2002; 359:1423-9.

34. Kollannoor-Samuel G, Wagner J, Damio G, Segura-Pérez S, Chhabra J, VegaLópez S, et al. Social support modifies the association between household food insecurity and depression among Latinos with uncontrolled type 2 diabetes. J Immigr Minor Health. 2011;13:982-9. https://doi.org/10.1007/s10903-011-9499-9.

35. Maharaj V, Tomita A, Thela L, Mhlongo M, Burns JK. Food insecurity and risk of depression among refugees and immigrants in South Africa. J Immigr Minor Health. 2016. https://doi.org/10.1007/s10903-016-0370-x.

36. Muldoon KA, Duff PK, Fielden S, Anema A. Food insufficiency is associated with psychiatric morbidity in a nationally representative study of mental illness among food insecure Canadians. Soc Psychiatry Psychiatr Epidemiol. 2013:48:795-803. https://doi.org/10.1007/s00127-012-0597-3.

37. Hadley C, Patil CL. Food insecurity in rural Tanzania is associated with maternal anxiety and depression. Am J Hum Biol. 2006:18:359-68.

38. Barbara AL, Anna MS, Craig G, Nancy D. Psychosocial Factors and Socioeconomic Indicators Are Associated with Household Food Insecurity among Pregnant Women. 2006.

39. Tofoli SMSM, Von Werne Baes C, Martins CMS, Juruena M. Early life stress, HPA axis, and depression. Psychol Neurosci. 2011;4:229-34. https://doi.org/10.3922/j.psns.2011.2.008.

40. Oladapo AL. Nutrition in pregnancy: mineral and vitamin supplements. Am J Clin Nutr. 2000;72(suppl):280S-90S.

41. Sánchez-Villegas A, Henríquez-Sánchez P, Ruiz-Canela M, Lahortiga F, Molero $P$, Toledo $E$, et al. A longitudinal analysis of diet quality scores and the risk of incident depression in the SUN project. BMC Med. 2015;13. https://doi.org/10.1186/s12916-015-0428-y.

42. Noonan $\mathrm{K}$, Corman $\mathrm{H}$, Reichman NE. Effects of maternal depression on family food insecurity. Econ Hum Biol. 2016;22:201-15. https://doi.org/10. 1016/j.ehb.2016.04.004.

43. Coad J, Pedley K. Iron deficiency and iron deficiency anemia in women. Scand J Clin Lab Invest. 2014;74:82-9. https://doi.org/10.3109/00365513. 2014.936694.

44. Swain, Penland, Johnson, Hunt. Energy, mood and attention did not consistenly improve with iron status in non-anemic women with moderate to low iron stores. FASEB J. 2006.

45. Kim J, Wessling-Resnick M. Iron and mechanisms of emotional behavior. J Nutr Biochem. 2014;25:1101-7. https://doi.org/10.1016/j.jnutbio.2014.07.003.

46. Jeon S, Kim YK. Molecular neurobiology and promising new treatment in depression. Int J Mol Sci. 2016;17:381. https://doi.org/10.3390/ijms17030381.

47. McGahan MC. Iron alters glutamate secretion by regulating cytosolic aconitase activity. AJP Cell Physiol. 2005;288:C1117-24. https://doi.org/10. 1152/ajpcell.00444.2004.

48. Sanacora G, Treccani G, Popoli M. Towards a glutamate hypothesis of depression. Neuropharmacology. 2012;62:63-77. https://doi.org/10.1016/j. neuropharm.2011.07.036

49. Mahenge B, Likindikoki S, Stöckl H, Mbwambo J. Intimate partner violence during pregnancy and associated mental health symptoms among pregnant women in Tanzania: a cross-sectional study. BJOG Int J Obstet Gynaecol. 2013;120:940-7. https://doi.org/10.1111/1471-0528.12185.
50. Ellsberg M, Peña R, Herrera A, Liljestrand J, Winkvist A. Candies in hell: women's experiences of violence in Nicaragua. Soc Sci Med 1982. 2000; 51:1595-610

51. Campos B, Schetter CD, Abdou CM, Hobel CJ, Glynn LM, Sandman CA. Familialism, social support, and stress: positive implications for pregnant Latinas. Cultur Divers Ethnic Minor Psychol. 2008;14:155-62. https://doi.org/10.1037/1099-9809.14.2.155.

52. Giesbrecht GF, Poole JC, Letourneau N, Campbell T, Kaplan BJ. The Buffering Effect of Social Support on Hypothalamic-Pituitary-Adrenal Axis Function During Pregnancy. Psychosom Med. 2013;75:856-62. https://doi.org/10.1097/PSY.0000000000000004.

53. Cohen S, Wills TA. Stress, social support, and the buffering hypothesis. Psychol Bull. 1985;98:310-57.

54. Gelaye B, Williams M, Lemma S, Deyessa N, Bahretibeb Y, Shibre T, et al. Validity of the patient health questionnaire-9 for depression screening and diagnosis in East Africa. Psychiatry Res. 2013;210:653-61. https://doi.org/10.1016/j.psychres.2013.07.015.

55. Spitzer RL, Kroenke K, Williams JB. Validation and utility of a self-report version of PRIME-MD: the PHQ primary care study. Primary care evaluation of mental disorders. Patient health questionnaire. JAMA. 1999;282:1737-44.

56. National Collaborating Centre for Mental Health. The treatment and management of depression in adults (Updated edition) National Clinical Practice Guideline 90. London: The British Psychological Society and The Royal College of Psychiatrists; 2010.

57. Bromet E, Andrade LH, Hwang I, Sampson NA, Alonso J, de Girolamo G, et al. Cross-national epidemiology of DSM-IV major depressive episode. BMC Med. 2011;9. https://doi.org/10.1186/1741-7015-9-90.

58. Patel V, Araya R, de Lima M, Ludermir A, Todd C. Women, poverty and common mental disorders in four restructuring societies. Soc Sci Med. 1999; 49:1461-71. https://doi.org/10.1016/S0277-9536(99)00208-7.

59. Havenaar JM, Geerlings MI, Vivian L, Collinson M, Robertson B. Common mental health problems in historically disadvantaged urban and rural communities in South Africa: prevalence and risk factors. Soc Psychiatry Psychiatr Epidemiol. 2008;43:209-15. https://doi.org/10.1007/s00127-007-0294-9.

60. Gureje O. Lifetime and 12-month prevalence of mental disorders in the Nigerian survey of mental health and well-being. Br J Psychiatry. 2006;188: 465-71. https://doi.org/10.1192/bjp.188.5.465.

61. World Health Organization. World Health Organization. Putting women first: Ethical and safety recommendations for research on domestic violence against women. Geneva. 2001. http://www.who.int/gender/violence/ womenfirtseng.pdf. Accessed 1 Feb 2017.

62. World Medical Association Declaration of Helsinki: Ethical Principles for Medical Research Involving Human Subjects. JAMA. 2013;310:2191. https://doi.org/10.1001/jama.2013.281053.

\section{Ready to submit your research? Choose BMC and benefit from:}

- fast, convenient online submission

- thorough peer review by experienced researchers in your field

- rapid publication on acceptance

- support for research data, including large and complex data types

- gold Open Access which fosters wider collaboration and increased citations

- maximum visibility for your research: over $100 \mathrm{M}$ website views per year

At BMC, research is always in progress.

Learn more biomedcentral.com/submissions 